\title{
Atuação do Enfermeiro Residente na Testagem Rápida para COVID-19: um relato de experiência
}

${ }^{1}$ Escola Superior de Ciências da Saúde/FEPECS/SES-DF, Programa de Pós-Graduação Lato Sensu- Residência Multiprofissional em Saúde do Adulto e do Idoso

RESUMO: $O$ artigo traz um relato de experiência observada por residente de Enfermagem nas testagens do modelo drive-thru acontecidas em Brasília- DF no mês de abril de 2020, em meio à pandemia causada por SARS-COV-2. Na mesma oportunidade, serão abordadas as dúvidas e questionamentos mais prevalentes por parte da população atendida, que foram respondidos tanto pessoalmente quanto por meio de banner vinculado à plataforma digital de uso comunitário por parte dos residentes e preceptores da Residência Multiprofissional em Saúde do Adulto e do Idoso.

Palavras-chave: Coronavírus, COVID19, educação em saúde, enfermagem, teste rápido.

\section{Performance of Nurse Residents in Rapid Testing for COVID-19: an experience report}

\begin{abstract}
This article brings an experience report observed by a nursing resident in the recent pandemic caused by SARS-COV-2 in tests accomplished by drive-thru model in April 2020, Brasília. The article also shows the common questions asked by the population which was answered personally and also indirectly through banners bounded to the shared digital platform of multi-professional residents and preceptors linked to adult and elderly health residency program.
\end{abstract}

Keywords: Coronavirus, COVID19, health education, nursing, rapid test. 


\section{INTRODUÇÃO}

Existem, atualmente, sete tipos de coronavírus reconhecidos por causarem infecções respiratórias em humanos. De forma geral, são vírus sazonais, que causam síndromes gripais, tendo, porém, também sido responsáveis por epidemias e por síndrome respiratória aguda grave (SRAG). O novo coronavírus, denominado SARS-CoV-2, é apontado como agente causador da doença COVID-19. Esse vírus, no espaço de 2 meses, migrou da China (onde foi detectado em 31 de dezembro de 2019, em Wuhan) para vários outros países e continentes (1), sendo que, no Brasil, em 26 de fevereiro, havia 1 caso confirmado segundo o Ministério da Saúde ${ }^{1}$.

Diante do impacto da doença no mundo e a crescente visibilidade conferida pela mídia, a pandemia logo começou a ser combatida no País por meio de campanhas de prevenção e ações voltadas à estratégia para a recuperação dos doentes, sendo os profissionais da Saúde os principais atuantes no tratamento direto ao paciente acometido e na orientação quanto às boas práticas de saúde.

Desde o século XIX, já se tem propostas de educação em saúde no Brasil centradas em condutas de higiene ${ }^{3}$.Com a pandemia do Covid-19, estratégias de conscientização da população quanto à necessidade de higiene pessoal e higiene respiratória foram adotadas de modo a seguir as recomendações da Organização Mundial da Saúde - OMS, cujo teor frisa o papel fundamental da educação da população e o papel desta, na prevenção da propagação da doença ${ }^{4}$.

A primeira medida direta seguida pelo Governo do Distrito Federal foi adotar o Distanciamento Social Ampliado, popularmente conhecido como "isolamento horizontal", recomendando o fechamento dos serviços não-essenciais e divulgando campanhas para conscientização das pessoas, a fim de que a população permaneça em casa praticando o 
isolamento social no intuito de evitar a rápida proliferação da doença - e o consequente congestionamento dos sistemas público e privado de saúde. Além do Distanciamento social, também foi recomendada a ampliação e divulgação das práticas de higiene e das medidas para evitar aglomerações ${ }^{5}$.

O objetivo primordialdo isolamento de toda a população é achatar a curva de crescimento da disseminação da doença, conferindo tempo aos serviços de saúde para melhor se equiparem e adequarem às particularidades da pandemia, com a criação de protocolos, convocação de funcionários e contratação de novos profissionais que foram capacitados para atuar nessa nova condição imposta pela singularidade do vírus ${ }^{5}$.

Atualmente, esferas governamentais vêm discutindo a transição para um Distanciamento Social Seletivo, em que apenas os grupos de risco e pessoas sintomáticas (e seus familiares) deveriam ficar em casa, combinado com a testagem em massa da população ${ }^{5}$

Inicialmente a proposta consiste em testar o maior número de pessoas por meio de utilização de "Testes rápidos" no esquema drive thru, nos quais a população se cadastra no site e agenda o dia da testagem de acordo com seu endereço de moradia. O ideal é que sejam testados pacientes sintomáticos do grupo de risco ou que convivam com alguém que faça parte dele.

Os testes utilizados no sistema único de saúde local são o Antibody Test da marca Wondfo e o Teste Rápido em Cassete 2019-nCon IgG e IgM, da marca Biotech. Ambos possuem sensibilidade para IgG e IgM, devendo ser aplicados em pacientes sintomáticos para maior sensibilidade do exame. A partir do $7^{\circ}$ dia de sintomas, o esperado é que o resultado dê positivo para a presença de IgM, atestando que o paciente é portador do vírus e que o corpo está combatendo a doença. Com aproximadamente 14 dias, o IgG se torna 
positivo, comprovando que o paciente já se encontra em período de convalescença, sendo o ideal que, após 28 dias do início dos sintomas, o IgG esteja positivo e o IgM não reagente ${ }^{6}$.

Sabendo que o enfermeiro é responsável por atividades de educação em saúde, o residente deve, neste momento de pandemia, participar ativamente da educação social, além de responder às demandas do SUS e necessidades da população, acompanhando os casos clínicos, atuando na assistência, bem como participando do processo de promoção à saúde, que inclui como atividade, a testagem rápida para COVID-19. Esse artigo é um relato de experiência de enfermeiros residentes em dois cenários de testagem rápida para COVID-19, realizadas em Brasília- DF, no mês de abril de 2020.

\section{MÉTODOS}

Trata-se de um estudo qualitativo, portanto, busca-se compreender a significância da aprendizagem de uma enfermeira residente, durante sua contribuição no processo de Testagem Rápida de Pacientes durante a pandemia por COVID-19.

\section{RESULTADOS}

Foi proposto aos residentes do Programa Multiprofissional de Saúde do Adulto e do Idoso um engajamento em atividades de educação em saúde relacionadas ao COVID-19, sendo esse tema uma demanda atual em quase todos os cenários. Um banner digital foi desenvolvido com orientações advindas das demandas apresentadas pela população durante o primeiro dia em que a autora participou do processo da testagem rápida realizado em um cenário de prática do Programa de Residência, localizado no Plano Piloto da cidade de Brasília, no Distrito Federal.

Observou-se incompreensão por parte da população quanto ao processo de testagem, período ideal para proceder ao teste, informações gerais sobre o COVID-19, além de 
percepção de informações equivocadas quanto ao teste, sendo que alguns pacientes acreditavam que aquela iniciativa estava ligada à imunização da população contra o coronavírus.

Constatada a demanda quanto a informações mais claras e cientificamente corretas, foi elaborado um banner que respondia às perguntas mais prevalentes: "Como me cadastro e agendo minha testagem?”, “Quem deve fazer o exame?”, “O exame é confiável?”, “Em quanto tempo tenho o resultado do exame?", “Como funciona o teste e como ele é realizado?", “Quem faz o teste e dá positivo está imune à doença?", "Se o resultado der positivo, para onde devo ir?", "Existe risco de alergia ou reação adversa ao teste?”.

O banner que respondia a todos estes questionamentos foi disponibilizado para a população por meio de postagem em plataforma digital Instagram na conta de uso coletivo dos residentes do Programa de Residência Multiprofissional de Saúde do Adulto e do Idoso da Escola Superior de Ciências da Saúde, vinculada à Secretaria de Saúde do Distrito Federal (@prmsai). Todas as informações contidas nele foram repassadas verbalmente para a população no segundo momento de testagem. 


\section{rona / rus oença}

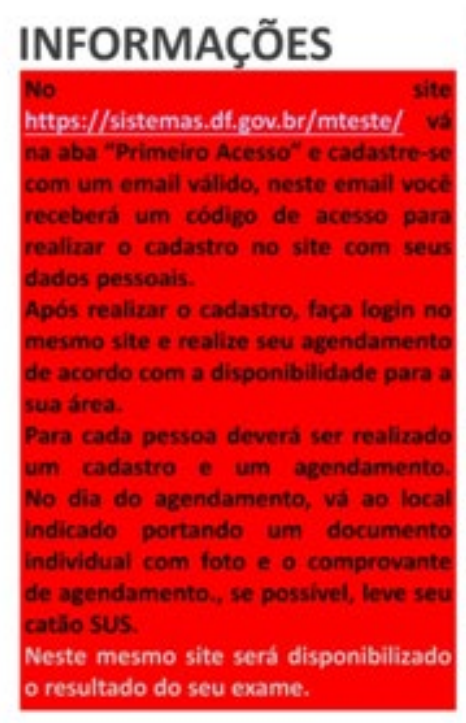

Quem deve fazer o exame?

Quem apresentar sintomas de

desconforto respiratório, febre, tosse

por mais de 7 dias.

Idosos acometides pelo CORONA

podem niso apresentar febre fique

atento pra outros possives sintomas

como : Irritabilidade, falta de apetite.

confusdo mental

Criancas normalmente apresentam

sintomas e carga viral mais baixa

correndo o risco de, mesmo doentes,

terem o resultado negativo, isso se

chama "Falso negativo", sendo

indicado que seja realizado o exame

de sangue que contem a resposta do

IgG e IgM.

- que devo saber sobre o teste rápido?

Você que vai realizar a testagem para COViD19 deve saber que todos os testes são validados pela ANVISA antes de serem usados na populaçăo! Isso assegura que os testes sào confiáveis!

Antes de realizar a aplicaçăo dos testes, os profissionais foram capacitados para minimizar as chances de erros.
Em quanto tempo sai o resultado do teste?

resultado fica pronto de acordo com o teste feito, em média de 10 a 20 minutos já se tem a resposta que será divulgada em até $72 \mathrm{~h}$ no mesmo site onde foi feito 0 agendamento para a testagem

Há perigo de contaminaç̧̌o durante realizaçăo do teste? $\mathbf{E}$ de alergia ao teste?

Os testes săo individuais e descartáveis, assim como a lanceta que será utilizada para perfurar o dedo. Nlio há relatos de alersias. A pessoa a ser testada näo deve sair do carro, isso minimiza o contato com outras pessoas que tambetm estăo no loca para realizar a testagem.

\section{Que teste estamos aplicando?}

A SES - DF está aplicando 2 testes, um deles é o "Antibody Test" da marca Wondfo, ele funciona da seguinte forma: é coletada uma gota de sangue que é depositada no cassete do teste e em seguida são depositadas 3 gostas do reagente, para ter certeza de que o teste está funcionando 1 linha deve aparecer na letra C indicando "Controle", se aparecer apenas a linha de Controle, 0 teste é considerado Negativo, se aparecerem 2 linhas no teste, sendo 1 em Controle e outra no Teste $(T)$ isso indica que está Positivo e que o teste é válido.

O outro teste que está sendo realizado é - Teste Rápido em Cassete 2019-nCon IgG e IgM da marca Biotech, ele é feito quase da mesma maneira do teste anterior sendo necessária 1 gota de sanque e 2 da solução tampão. Esse teste indica em C (Controle) que o teste está funcionando, em Ig G - quando aparece a listra, que a pessoa está imunizada ou em periodo de convalescença (se recuperando da doenca), no caso da listra aparecer em $\lg \mathrm{M}$ indica que a pessoa está infectada há 7 dias ou menos.

Qu sela, em qualquer um dos 2 testes é necessária que aparesa a linha $c$ de Controle para o teste ser válido, se a linha $\mathrm{C}$ năo aparecer, o exame será repetido.
Quem faz o teste fica imunizado?

Năol E importante saber que ainda nå ha nenhuma vacina contra a SARS-Covid19.

\section{Sintomas:}

É possivel estar com a COVID-19 por até 14 dias antes de apresentar os sintomas como febre, cansaço, tosse seca, dificuldade para respirar.

A maioria das pessoas (cerca de $80 \%$ ) se recupera da doença sem tratamentos especiais. Em casos mais raros, ela pode ser grave e até fatal. Idosos e pessoas com outras condiçōes médicas (como asma, diabetes e doença cardiaca) săo mais vulneráveis a quadros graves. Tendo sintomas, procure a sua Unidade Básica de Saúde, lá eles irăo informá-lo melhor sobre a doença e como se cuidar!

\section{Tratamentos: \\ Năo há, até o momento, nenhum medicamento especifico para tratar ou prevenir o coronavirus (COVID-19). Sendo a higiente das mios uma das formas mais eficazes de previnir o coltzigio. \\ o tratamento pode variar de acordo com o quadro apresentado pelo paciente, por isso, mesmo com os sintomas leves, o doente deve procurar a Unidade Básica de Saúde.}

Resultado POSITIVO, o que fazer?

Ao obter um resultado positivo, o paciente deve procurar a UBS para maiores orientaçōes de acordo com o quadro. Pode ser solicitado que exame seja repetido.

Para maiores informaçōes siga nosso instagram@prmsai conteúdo científico atualizado por equipe multiprofissional.

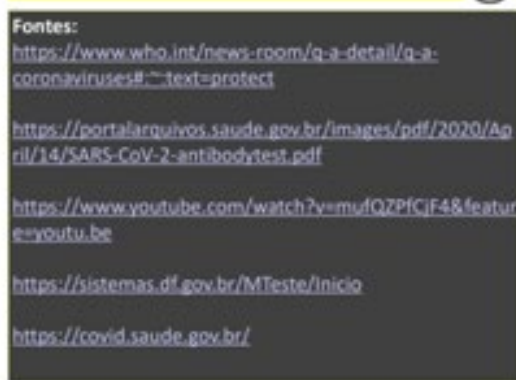

Figura 1: Banner Informativo sobre a Testagem Rápida para COVID-19 
Neste segundo momento, em outro cenário, foi realizada a educação em saúde, passando-se pelos veículos com as informações do banner e esclarecendo à população. A receptividade foi satisfatória, sendo que muitos agradeceram pelas informações prestadas e se comprometeram em disseminá-las.

Além de prestar informações à população, participou-se ativamente na triagem dos pacientes que chegavam. Algumas pessoas compareceram ao local do teste sem terem realizado agendamento prévio, sendo instruídas sobre como o teste funciona e qual o grupo que deveria realizar o exame e do procedimento necessário para agendá-lo. Também houve do Programa de Residência, na coleta dos exames.

Cabe observar que, embora contraindicado, parte dos usuários do SUS que foram realizar o exame não apresentava sintomas há 7 dias, sendo que a maioria alegava que não tinha contato com idosos nem era grupo de risco, mas achava válida a oportunidade de testar para saber se estava doente ou já imune à doença, contrariando a indicação do teste.

\section{DISCUSSÃO}

Estudos afirmam que a letalidade do vírus está diretamente ligada à presença de comorbidade, principalmente de doenças pulmonares, Diabetes Mellitus e doenças cardiovasculares, bem como à idade do acometido. As manifestações clínicas da COVID-19 são menos frequentes e graves em crianças, exceto nas menores de 1 ano. ${ }^{9}$

Um possível viés da aplicação dos testes rápidos, considerando o processo utilizado, é que a população testada pode apresentar anticorpos abaixo da faixa de cut-off, dando um resultado negativo mesmo para as que tiveram algum contato com o vírus. ${ }^{10}$

O teste deve ser utilizado de forma a confirmar o diagnóstico do paciente quando já há um quadro de sintomas que coincidam com o esperado para acometidos pelo COVID-19 
há pelo menos 07 dias, dando uma sensibilidade de $86 \%{ }^{11}$, segundo o fabricante. Quando realizado fora deste período, a sensibilidade diminui, acarretando o risco de falsos negativos..$^{6,9,10}$

O processo de realização do teste pode alterar o resultado. Segundo o vídeo de instrução disponibilizado pelo canal do youtube do Matriciamento $\mathrm{SESDF}^{8}$, a primeira gota de sangue deve ser desprezada e a segunda colhida sem bolhas. Outra particularidade é que a solução tampão deveria ser depositada com 3 gotas, sendo que duas delas devem ser depositadas imediatamente após a gota de sangue ser colocada no seu poço e a terceira gota do tampão deveria ser pingada após 10 segundos da segunda gota da solução.

Segundo as orientações do fabricante, o exame deve ser lido 15 minutos após ter sido colhido, com o tempo máximo para verificar o exame o de 20 minutos ${ }^{7,8}$, sendo que extrapolar o tempo determinado pode acarretar em erros no resultado do exame.

Um dos principais problemas dos exames apresentarem falsos negativos é que, falsamente diagnosticada, a pessoa tende a se despreocupar quanto às medidas de segurança, podendo transmitir a doença. Outro problema é que, caso os sintomas piorem ou persistam e o doente realize nova testagem no tempo correto, o exame poderá vir com o resultado positivo, gerando "desconfiança" social quanto à sua acurácia.

Cabe ressaltar que os exames não existem em quantidade suficiente para que toda a população teste mais de uma vez, portanto, em determinado momento, poderá não ter acesso ao exame, um paciente com suspeita de COVID-19, sintomático há 07 dias e que poderia, de fato, confirmar o diagnóstico. Sendo assim, é essencial a conscientização social quanto ao teste. ${ }^{6,9}$

A desconfiança social aumenta à medida em que fake news são disseminadas cotidianamente. Com a maior facilidade de comunicação que existe hoje, a informação chega 
cada vez mais rápido a mais pessoas, essas ferramentas de comunicação, quando usadas conscientemente, podem ajudar a diminuir a disseminação do vírus e a prevenir várias doenças $^{12}$.

Estudos afirmam que, de acordo com o posicionamento político, é mais fácil que uma pessoa aceite uma informação sem questioná-la ${ }^{12}$. Os profissionais de saúde são importantes instrumentos na desconstrução de falsas informações e para tanto, devem ampliar sua comunicação com a sociedade, em inúmeros canais, não se limitando à comunicação estritamente científico-acadêmica ${ }^{12}$.

\section{CONCLUSÃO}

Fica evidente por meio deste relato de experiência que embora a população receba grande número de informações sobre a COVID-19, não havia o conhecimento necessário por parte de significativa parte dos pacientes que procuraram a testagem rápida, desconhecendo aspectos básicos sobre o processo, sintomas de COVID-19, grupos de risco, cabendo aos profissionais residentes do Sistema Único de Saúde, atuar ativamente na promoção da educação em saúde, divulgando dados científicos relevantes, adequando sua linguagem para estabelecer vínculo com os pacientes e, com isso, diminuindo a propagação das fake news que promovem o medo e causando perdas para a sociedade como um todo.

Há necessidade de avaliação dos Kits utilizados para testagem rápida de COVID-19, bem como de treinamento eficaz dos profissionais que realizam o procedimento, a fim de aumentar a especificidade do teste.

Tendo em vista que a inscrição para agendamento do teste é realizada via internet, poderia haver um alerta exclusivo sobre a testagem em crianças, indicando que os testes disponíveis no sistema de saúde local apresentam menor sensibilidade para esta faixa etária, 
devendo ser indicados RT-PCR em tempo real, detecção do vírus SARS-CoV2, Influenza ou VSR, nos casos de sintomáticos respiratórios.

A inclusão dos sintomas do paciente na ficha de agendamento dos testes diagnósticos para COVID-19, via internet, também poderia reduz o desperdício de Kits, e propiciando à população, conhecimento básico do quadro clínico da doença; riscos, benefícios, sensibilidade e especificidade dos exames disponíveis, haja vista a escassez de recursos do Sistema Único de Saúde.

\section{REFERÊNCIAS BIBLIOGRÁFICAS}

1. Lana RM, et al. Emergência do novo coronavírus (SARS-CoV-2) e o papel de uma vigilância nacional em saúde oportuna e efetiva. Cad. SaúdePública [Internet]. 2020 [cited 2020 May 02] ; 36( 3 ): e00019620. Available from: http://www.scielo.br/scielo.php?script=sci_arttext\&pid=S0102$311 X 2020000300301$

2. Brasil. Ministério da Saúde. [Internet]. 2020 [cited 2020 May 01]. Available from: https://www.coronavirus.ms.gov.br/

3. Da Silva AAM. Sobre a possibilidade de interrupção da epidemia pelo coronavírus (COVID-19) com base nas melhores evidências científicas disponíveis. Rev Bras Epidemiol 2020; 23: E200021 [Internet]. 2020 [cited 2020 May 01]. Available from: https://www.scielosp.org/article/rbepid/2020.v23/e200021/

4. World Health Organization. WHO Director-General's opening remarks at the media briefing on COVID-19 - 5 March 2020 [Internet]. World Health Organization; 2020 [cited 2020 Mar 30]. Available from: https://www.who.int/dg/speeches/detail/whodirector-general-s-opening-remarks-at-the-media-briefing-on-covid-19---5-march2020 
5. Brasil. Ministério da Saúde. Boletim Epidemiológico 8-COE: Coronavírus - 09 de abril de 2020. [Internet]. 2020 [cited 2020 Mar 30]. Available from: https://www.saude.gov.br/images/pdf/2020/April/09/be-covid-08-final-2.pdf

6. Brasil. Ministério da Saúde. SARS-CoV-2 Teste Rápido Imunocromatográfico. [Internet]. 2020 [cited 2020 Mar 30]. Available from: https://portalarquivos.saude.gov.br/images/pdf/2020/April/14/SARS-CoV-2antibodytest.pdf

7. Paula $\mathrm{CC}$, et al. Modos de condução da entrevista em pesquisa fenomenológica: relato de experiência. Revista Brasileira de Enfermagem, 67(3), 468-472. [Internet] 2020 [cited 2020 Mar 30]. Available from: https://www.scielo.br/scielo.php?pid=S0034$71672014000300468 \&$ script $=$ sci_arttext\&tlng=pt

8. Treinamento teste rápido COVID-19. Vídeo explicativo do Matriciamento SESDF. [Internet]. 2020 [cited 2020 Mar 30]. Available from: https://www.youtube.com/watch?v=mufQZPfCjF4\&t=211s

9. Cheng MP, et al. Testes diagnósticos para síndrome respiratória aguda grave decorrente do coronavírus -2: uma revisão narrativa. Tradução livre de artigos científicos sobre o Covid-19. [Internet] 2020 [cited 2020 Mar 30]. Available from: http://www.toledo.ufpr.br/portal/wp-content/uploads/2020/04/Testesdiagno_sticos-para-Coronavi_rus-2-relacionado-a_-Si_ndrome-Respirato_riaAguda.pdf

10. Brasil. Secretaria de Estado de Saúde do Rio Grande do Sul. Guia para a utilização dos testes rápidos de anticorpos SARS-CoV-2 antibodytest ${ }^{\circledR}$ da marca Wondfo. [Internet] 2020 [cited 2020 May 01]. Available from: 
https://saude.rs.gov.br/upload/arquivos/202004/16161242-guia-utilizacao-testerapidos-final-3.pdf

11. Brasil. Ministério da Saúde. Acurácia dos testes diagnósticos registrados para a covid-19. [Internet]. 2020 [cited 2020 May 02]. Available fromhttps://www.sbmfc.org.br/wpcontent/uploads/2020/04/Acur_cia_dos testes_p ara_COVID_19_1586558625.pdf.pdf

12. Junior JHS, et al. Da Desinformação ao Caos: uma análise das Fake News frente à pandemia do Coronavírus. Cadernos de Prospecção - Salvador, v. 13, n. 2, Edição Especial, p. 331-346, abril, 2020 [Internet] 2020 [cited 2020 May 02]. Available from:https://cienciasmedicasbiologicas.ufba.br/index.php/nit/article/view/35978/20 912 